\title{
Psychotherapy and trainees
}

\section{Current practice, its perceived importance and the question of lay counsellors}

\author{
Peter Byrne and David Meagher
}

The value and efficacy of psychotherapy is currently being debated both within (Gabbard et $a l, 1997)$ and outside the profession. One commentator has spoken of psychotherapy's populist synonym 'counselling", as the "valium of this era", where counselling "does not cause the same clouding of consciousness as drugs, but its side-effects are twice as bad" (Dalrymple, 1996).

Royal College of Psychiatrists' guidelines have consistently emphasised the importance of psychotherapy training for trainees (Royal Medico-Psychological Association, 1971; Grant et al, 1993). Previous studies have compared these recommendations with the realities of practice and this survey records the experiences of a large group of trainees in Ireland, in order to establish current trends and allow comparison with these studies. It also explores the relationship between psychotherapy experience and a number of other training parameters.

Recent years have seen a growth in nonmedical counsellors, driven by the health services' attraction to their lower costs (relative to medically-trained personnel) and by perceptions about medical counsellors among general practitioners (Mutale, 1995). Attitudes of trainees to non-medical psychotherapists, who may nor may not be members of the interdisciplinary team, are presented.

\section{The study}

A questionnaire was administered to all psychiatric trainees in the Eastern region of Ireland and yielded 138 completed replies, a response rate of $80.2 \%$. The details and demographics of respondents are recorded elsewhere (Meagher et al, 1997). One section asked trainees a number of specific questions about their experiences of psychotherapy training and their general views in this area.

\section{Findings}

\section{Current practice}

Trainees were asked if they had received any formal training in the assessment of patients for psychotherapy (see Table 1). Trainees also indicated if they had treated patients under supervision using any of a number of treatments (Table 2).

Trainees who had practised psychotherapy (any modality) were compared to those who had not (see Table 3). Trainees who had undertaken psychotherapy indicated for how long each month they had access to a supervisor. For dynamic psychotherapy, 43 trainees had a mean 2.52 hours supervision monthly. Others were group psychotherapy ( $n=19) 2.27$ hours; cognitive-behavioural therapy $(n=23) 2.17$ hours; and family therapy ( $n=17) 2.35$ hours.

This information identified a third group who had received supervision in accordance with College guidelines, that is, experience of each modality, with minimum time allocations, for example one hour supervision each week for dynamic therapy (Grant et al, 1993). Six trainees met these requirements (see Table 3 ).

Table 1. Formal training in the assessment of patients for psychotherapy

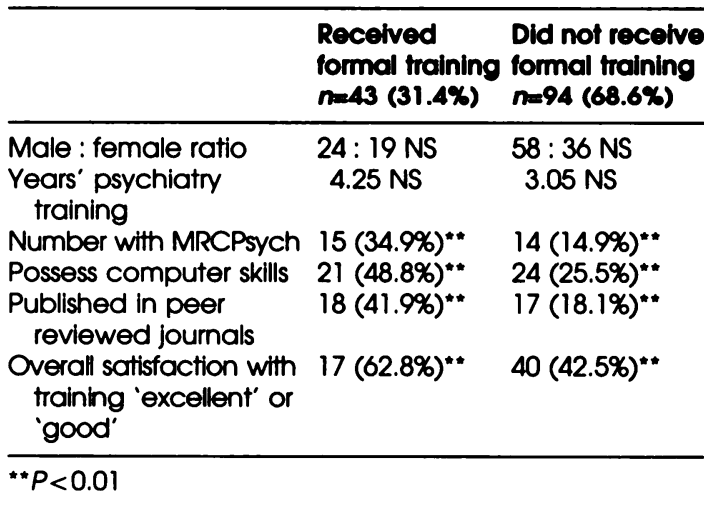


TRAINEES' FORUM

Table 2. Trainees who have treated patients with psychotherapy, with treatment modality

\begin{tabular}{|c|c|c|c|c|c|c|c|}
\hline \multirow[b]{2}{*}{ Study } & \multirow[b]{2}{*}{$\begin{array}{l}\text { Pre- } \\
\text { MRCPsych }\end{array}$} & \multirow[b]{2}{*}{$\begin{array}{l}\text { Post- } \\
\text { MRCPsych }\end{array}$} & \multirow{2}{*}{$\begin{array}{l}\text { Training in the } \\
\text { assessment of } \\
\text { patients for } \\
\text { psychotherapy } n(\%)\end{array}$} & \multicolumn{3}{|c|}{ Psychotherapy $n$ (\%) } & \multirow[b]{2}{*}{ Family } \\
\hline & & & & Dynamic & СBT & Group & \\
\hline $\begin{array}{l}1 \\
2\end{array}$ & $\begin{array}{r}9 \\
77\end{array}$ & $\begin{array}{l}13 \\
50\end{array}$ & $11(50)$ & $18(82)$ & $4(18)$ & $2(9)$ & $10(45)$ \\
\hline 3 & 6 & 13 & $15(79)$ & & $04(20)$ & & \\
\hline 4 & 0 & 90 & & $70(78)$ & $64(71)$ & $52(58)$ & $51(56)$ \\
\hline 5 & 108 & 30 & $43(31)$ & $47(34)$ & 25 (18) & $26(19)$ & 20 (15) \\
\hline
\end{tabular}

CBT, Cognitive-Behavioural Therapy.

1. Arnott et al (1993) $(n=22)$.

2. Drummond \& Ramsey (1996) ( $n=127)$.

3. Hamilton \& Tracy (1996) $(n=19)$.

4. Hwang \& Drummond (1996) $(n=90)$.

5. Byrne \& Meagher (1997) ( $n=138)$.

Table 3. Trainees who have treated patients with psychotherapy under supervision

\begin{tabular}{llll}
\hline & $\begin{array}{l}\text { Treated } \\
\text { patients with } \\
\text { psychotherapy } \\
(n=68)\end{array}$ & $\begin{array}{l}\text { Did not treat any } \\
\text { patients with } \\
\text { psychotherapy } \\
(n=70)\end{array}$ & $\begin{array}{l}\text { Treated patients in all } \\
\text { four modallies, meeting } \\
\text { College guidelines } \\
(n=6)\end{array}$ \\
\hline Year's training in psychiatry & $3.7 \mathrm{NS}$ & $3.2 \mathrm{NS}$ & $8.7^{*}$ \\
Number with MRCPsych & $19 \mathrm{NS}$ & $11 \mathrm{NS}$ & $5^{* *}$ \\
Possess computer skills & $28^{*}$ & $17^{*}$ & $4^{* *}$ \\
Published in peer reviewed journals & $24^{* *}$ & $11^{* *}$ & $5^{* *}$ \\
Overall satisfaction with training 'excellent' or 'good' & $37 \mathrm{NS}$ & $30 \mathrm{NS}$ & $5^{*}$ \\
\hline
\end{tabular}

${ }^{*} P<0.05$

$* P<0.01$

Value of psychotherapy

In the context of overall training, psychotherapy training was rated as 'very relevant' $57 \%$, 'relevant' $41 \%$, with $2 \%$ 'irrelevant'. Trainees were also asked whether they thought a trained psychotherapy supervisor should be available to all trainees: $129(99 \%)$ replied yes.

All trainees were asked if they were satisfied with their training in a number of key areas, including the three psychotherapeutic modalities listed in Table 4. Those who had had direct experience of psychotherapy were significantly more satisfied with this training (Table 5).

\section{Suitability of psychotherapists}

Trainees were asked to indicate (yes or no) the suitability of the following persons to conduct psychotherapy: psychiatrist, clinical psychologist, social worker, general practitioner (GP) and lay counsellor. They were presented in that order, without any accompanying explanations. Sixteen trainees deemed all five suitable. They were less likely to have had any psychotherapy training (5/16 had this experience), but this trend was not significant. There was no relationship between the total number of categories chosen and psychotherapy experience.

Eighteen trainees considered that only a psychiatrist could practise psychotherapy with eight stating that a clinical psychologist (i.e. psychologist alone) could do so. Only one of these eight trainees had experience of psychotherapy training. Forty-eight trainees, who did not include any other group, approved both professionals. The subtotal, 74 (68.9\%), was compared to the remainder in relation to the presence of

Table 4. Trainees' satisfaction with specific aspects of training

\begin{tabular}{lll}
\hline Training aspect & Satisfied & Not satistied \\
\hline Child psychiatry & $89 \%$ & $11 \%$ \\
Liaison psychiatry & $83 \%$ & $27 \%$ \\
Violence management & $37 \%$ & $63 \%$ \\
Dynamic psychotherapy & $21 \%$ & $79 \%$ \\
Cognitive-behavioural & $20 \%$ & $80 \%$ \\
$\begin{array}{l}\text { psychotherapy } \\
\text { Family therapy }\end{array}$ & $17 \%$ & $83 \%$ \\
\hline
\end{tabular}


Table 5. Trainees' satisfaction with psychotherapy training based on experience

\begin{tabular}{|c|c|c|c|c|c|}
\hline \multirow[b]{2}{*}{ Treatment modality } & \multicolumn{2}{|c|}{$\begin{array}{l}\text { Group with direct experience } \\
\text { of psychotherapy }\end{array}$} & \multicolumn{2}{|c|}{$\begin{array}{l}\text { Group with no direct } \\
\text { experience of psychotherapy }\end{array}$} & \multirow[b]{2}{*}{$P$} \\
\hline & Satisfled & Not satisfled & Satisfled & Not satisfied & \\
\hline $\begin{array}{l}\text { Dynamic psychotherapy } \\
\text { Cognitive-behavioural psychotherapy } \\
\text { Family therapy }\end{array}$ & $\begin{array}{l}18 \\
14 \\
14\end{array}$ & $\begin{array}{l}36 \\
37 \\
38\end{array}$ & $\begin{array}{l}4 \\
6 \\
3\end{array}$ & $\begin{array}{l}47 \\
45 \\
45\end{array}$ & $\begin{array}{l}P=0.001 \\
P=0.04 \\
P=0.006\end{array}$ \\
\hline
\end{tabular}

psychotherapeutic experience. Although they were more likely to have had this experience, this trend was not significant $(P=0.1)$.

Seventy-six respondents $(57.1 \%)$ judged the GP as a suitable person to practise psychotherapy, $98(73.7 \%)$ stated that any, or all of four other persons were suitable except the social worker, with $111(83.5 \%)$ stating that any or all of the four other persons were suitable except the lay counsellor. These trainees showed the same distribution of experience in years and in training as the wider group. Thirty-three indicated approval for the social worker, with 22 for the lay counsellor.

\section{Comment}

This study reports the views of a large group of trainees, and explores these views in the context of other areas of experience and opinion. In addition to the limitations of any questionnaire-based study, our results must also be seen in the context of a high proportion of trainees who had not yet attained MRCPsych (see Table 2). There may be a perception among trainees that psychotherapy is part of higher training, that is something to pursue after attaining MRCPsych. In practice the majority of teaching time for pre-membership trainees is exam orientated.

\section{Current practice}

Less than half of those questioned reported that they had direct experience of psychotherapy. Less than one-third had had formal training in the assessment of patients for psychotherapy. This group did not represent a group new to psychiatry, with an average of 3.05 years training. Table 2 compares the stated experiences with previous studies, and our figures compare poorly with these. From our survey it would appear that in Ireland a substantial proportion of psychiatrists in training have no practical psychotherapeutic input into that training. Where training is provided, the amount of supervision falls short of College guidelines in all but a few cases.

\section{Value of psychotherapy}

When asked to rate the importance of psychotherapy, the vast majority reported this training to be either relevant or highly relevant. The proposition that a supervisor be provided for all trainees was accepted almost unanimously.

In a previous study by Castle et al (1994), trainees rated training opportunities as 'poor' in psychodynamic therapy $(28 \%)$, cognitive-behavioural therapy $(46 \%)$ and family therapy (38\%). These ratings are important in that they represent the highest dissatisfaction ratings (with one exception, management of violence) in a survey of 137 MRCPsych Part II candidates (Castle et al, 1994). In Table 2, we present even higher dissatisfaction rates, and these figures may be directly related to the deficits in training we have described. Trainees judge this training important and the lack of opportunities is seen as a weakness of their training. Our findings also support the hypothesis that deficits in training are related to supply of opportunities and supervisors, rather than low demand from trainee psychiatrists.

American psychiatry has experienced the decline of psychotherapy as the dominant feature of psychiatric training. Wallerstein (1991) charted the decline over 50 years in psychotherapy teaching (as a percentage of total teaching time in an average Residency programme) from 50 to $2.5 \%$. Bradbury et al (1996) found the majority of psychiatrists recognised the need for and efficacy of psychotherapy. We confirm this finding in identifying psychiatric trainees who consider psychotherapy important. and when they receive training and supervision are significantly more satisfied with both this specific aspect of training and their training in general.

Our findings also challenge the stereotype of the psychotherapeutically orientated trainee as female and someone who does not develop other interests. They have passed exams, researched and published, and are significantly more computer literate than their untrained peers. In this respect, those who complete any psychotherapy training, but especially those who have met College guidelines, could be described as role models for all psychiatrists in training. 


\section{Suitability of psychotherapists}

Trends were less obvious in this area. A minority of trainees regarded psychiatrists alone as suitable therapists, over half stated that only psychiatrists and/or psychologists were appropriate here and a similar number included the GP. No parameters could separate out these two groups.

Social workers and lay counsellors were frequently absent from this suitability list, with high numbers of trainees (74 and $84 \%$ respectively) believing that these persons were not suitable therapists. Again, no parameters could separate out these groups. With regard to social workers, one explanation could be the confusion in trainees' minds between psychiatric social workers and community care social workers. Under recent Irish legislation, the latter group may come into conflict with psychiatrists over child care issues (O’Boyle, 1996, personal communication). In a recent survey of counselling in one district, none of the team's five social workers saw themselves as providing counselling to their patients (Arnott et al, 1996).

Lay counsellors are unacceptable to a majority of respondents. This opinion was independent of psychotherapy experience, and could not be attributed to a 'sour grapes' attitude (we're not trained to do it, so why should they do it?) among trainees. At one level their concerns are shared by GPs in Ireland, whose recent guidelines (O'Carroll \& O'Riordan, 1996) record reservations about the supervision and professional indemnity of lay counsellors. Interestingly in the UK, general practices which have formal links with mental health services, are more likely to employ a lay counsellor (Mutale et al, 1995).

\section{Conclusions}

Low numbers of trainees gained any experience and supervision times were below guidelines, with only a small minority meeting College guidelines. Trainees were unhappy with their current opportunities in this area. Favourable findings were that any training was associated with higher satisfaction levels, and well-rounded trainees. Respondents valued psychotherapy highly despite lower levels of training than previously published studies. The majority believed psychiatrists, psychologists and GPs to be suitable psychotherapists, but voiced reservations about non-medical counsellors.

\section{References}

ARnOtT, S., Wilkinson, E. \& AYLARD, P. (1993) A survey of psychotherapy experience among psychiatric registrars. Psychiatric Bulletin, 17, 721-723.

-. Dorkins, E. \& AYLARD, P. (1996) The Sourcerer and the Apprentice. A study of psychotherapy and counselling occurring in a district wide general adult psychiatric service. Psychiatric Bulletin, 20, 609-611.

BRADBURY, S., O'BRIEN, L. \& GÖPFERT. M. (1996) Psychotherapy - a survey of psychiatrists attitudes. beliefs and practice. Psychiatric Bulletin. 20. 15-19.

CASTLE, D., REEVE, A.. IVINSON, L., et al (1994) What do we think about our training? Psychiatric Bulletin, 18, 357359.

DALRYMPLE, T. (1996) Seen a happy counsellor? Sunday Times, 7 January.

DRUMMOND, L. \& RAMSAY, R. (1996) Trainees' experience and attitudes to behavioural-cognitive psychotherapy. Psychiatric Bulletin, 20, 351-353.

GABBARD, G., LAZAR, S., HORNBERGER, J., et al (1997) The economic impact of psychotherapy: a review. American Psychiatry, 164, 147-155.

Grant, S., Holmes, J. \& Watson, J. (1993) Guidelines for psychotherapy training as part of general professional training. Psychiatric Bulletin, 17, 695-698.

HAMILTON, R. \& TRACY, D. (1996) A survey of psychotherapy training among psychiatric trainees. Psychiatric Bulletin, 20, 536-537.

HWANG, K. \& DRUMMOND. L. (1996) Psychotherapy training and experience of successful candidates in the MRCPsych. Psychiatric Bulletin, 20, 604-606.

MEAGHER, D., QUiNN, J., O'MAHONY, E., et al (1997) Trainee attitudes towards their training and its supervision. Irish Joumal of Psychological Medicine, 14, 20-23.

MutALE, T. I. R. (1995) Employment of counsellors and mental health professionals by fundholding general practices. Psychiatric Bulletin. 19, 627-630.

O'CARROLL, A. \& O'RIORDAN, M. (1996) Counselling in Practice: A Guide for General Practitioners. Dublin: Irish College of General Practitioners.

ROYAL MEDICO-PSYCHOLOGICAL ASSOCIATION (1971) Guidelines for the training of general psychiatrists in psychiatry. British Journal of Psychiatry, 119, 555-557.

WALLERSTEIN, R. (1991) The future of psychotherapy. Bulletin of the Menninger Clinic, 55, 421-443.

*Peter Byrne, Senior Registrar in Psychiatry, St Vincent's Hospital, Elm Park, Dublin 4; and David Meagher, Senior Registrar in Psychiatry, St Davnett's Hospital, Monaghan

*Correspondence 